\title{
Determining the Extractive Casting Mold of Intimate Platforms through Document Theory
}

\author{
Benedict Salazar Olgado \\ University of California, Irvine \\ Irvine, California, USA \\ bolgado@uci.edu
}

\author{
Lucy Pei \\ University of California, Irvine \\ Irvine, California, USA \\ lucyp1@uci.edu
}

\author{
Roderic Crooks \\ University of California, Irvine \\ Irvine, California, USA \\ crooksr@uci.edu
}

\begin{abstract}
This paper introduces document theory as a mechanism to analyze intimate platforms as sociotechnical systems. The theory, developed in documentation studies and applied to HCI, focuses on the casting mold or how agents, through particular means and modes, produce documents that govern social relations. We studied the process of creating a profile by identifying and mapping out the fields asked among the ten most popular online dating apps in the US. By looking at dating profiles as documents and their creation as a process of documentation, we argue that the current casting mold of these intimate platforms is designed to extract profit via invisibilization of labor in digital networks leading to the emergence of a constrained rational market agent. Our study illustrates how document theory makes visible the assumptions of technological systems, calling on us to imagine alternatives beyond incremental design changes given broader structural realities of market and power.
\end{abstract}

\section{Author Keywords}

Intimate platforms; Document Theory; Political economy

\section{CCS Concepts}

-Human-centered computing $\rightarrow$ HCI theory, concepts and models;

\section{INTRODUCTION}

The dating industry continues to grow, as it is projected to be worth $\$ 3.2$ billion by 2020 with $70 \%$ of its revenue generated by online sites and dating apps [24]. Forecasters predict continued growth in user base based on several demographic and technological factors: the increase in the single population in the United States and other markets, expanded access to the Internet by the general population, and the commercial success of smartphones and apps in all kinds of consumer arenas [29]. For example, 22\% of Americans ages 18 to 24 report using online dating apps in 2016, comprising a fourfold increase in just three years [36]. This growth is aligned with

\footnotetext{
Permission to make digital or hard copies of all or part of this work for personal or classroom use is granted without fee provided that copies are not made or distributed for profit or commercial advantage and that copies bear this notice and the full citation on the first page. Copyrights for components of this work owned by others than the author(s) must be honored. Abstracting with credit is permitted. To copy otherwise, or republish, to post on servers or to redistribute to lists, requires prior specific permission and/or a fee. Request permissions from permissions@ acm.org.

CHI'20, April 25-30, 2020, Honolulu, HI, USA

(C) 2020 Copyright held by the owner/author(s). Publication rights licensed to ACM. ACM ISBN 978-1-4503-6708-0/20/04 . . \$15.00

DOI: http://dx.doi.org/10.1145/3313831.3376850
}

the increased social acceptance of various forms of computermediated dating and a reduction in the stigma traditionally associated with using such platforms to meet potential romantic partners, find new friends, and pursue casual encounters [8, $35,36,41]$. Given that users pursue ends beyond dating on what are generally classed as dating apps, Hutson et al. favor the term intimate platforms to include a broader view of how intimacy is expressed and pursued [21].

Hutson et. al. argue that design features of intimate platforms can exacerbate or mitigate discrimination and thus call for design features that can mitigate bias and exclusion [21]. Their work, together with other HCI research, focuses on questions of technologically determined effects of these platforms on identity presentation [2, 40] and social relations [21, 28]. These studies revolving around technology design and user behavior, though valid and important, may continue to obscure the fundamentally market-based nature of intimate platforms. Roscoe and Chillas point out that corporate owners of intimate platforms "deploy the rhetoric of scientific method to claim ownership of, and the right to derive entrepreneurial rents from, the social context of human partnerships" [34]. Sam Yagan, founder of OKCupid, confirms their point bluntly in a 2013 interview, saying, "You give us data. We give you dates," [26].

This paper picks up and broadens Hutson et al.'s call to develop theories and practices that interrogate the "design, operation, and role of intimate platforms," [21]. In response, our main objective is to introduce and develop document theory as a mechanism to analyze such a sociotechnical system embedded in market logic. Though document theory has rarely been applied to HCI [22], its broad, flexible, and complementary approach is a way to bring political economy into our understanding of systems which is at times obscured by the limits of design thinking. By looking at dating profiles as documents and their creation as a process of documentation, we determine that the current casting mold of intimate platforms is made to create objects constrained and reproduced for profit extraction. Based on this analysis, we discuss the ways in which intimate platforms are a form of digitally-mediated capital accumulation, through the creation of the user as a rational market actor who must operate within the constraints of a nonneutral infrastructure. Through document theory we describe and make explicit the extractive mechanisms of technological systems used in everyday life, and this calls on our community to imagine alternatives beyond incremental design changes as 
we take into consideration broader structural issues of market and power.

\section{RELATED WORK}

\section{Marketplaces of Intimacy}

The history of intimate platforms is also the history of the birth and growth of a complex, technologically advanced media landscape wherein corporations sell services that claim to help people find romantic partners [19]. A pervasive, totalizing sense of market relations informs these developments of intimate platforms and their antecedents. From the early text-based matrimonial ads on periodicals [32] to the rise of formal marriage market intermediaries in the 20th century [1], various entities and technologies have mediated through documents the search for eligible and suitable partners shaped by the logic of supply and demand. This framework was eventually adopted by computer-assisted, profile-based dating that began in affluent, academic settings in the 1950s and 60s [16]. With the growth of the World Wide Web and personal computing, the dating industry acquired new channels for attracting customers while still drawing largely on the established profilebased system of documentation [29].

Studies on intimate platforms illustrate how market logic continues to shape its design, operations, and use. Heino et. al.'s study interviewed participants in one of the largest online dating services [19]. Their results revealed that the marketplace metaphor and logic resonated with participants, leading them to employ several strategies in line with this perspective. This is echoed in Hobbs et. al.'s survey and in-depth interviews of intimate platform users who acknowledge the "need to engage in self-branding activities to market themselves as desirable commodities in a crowded relationship marketplace" [20]. In addition, ecosystems surrounding these intimate platforms exist to support and game the market. For example, Zytko et. al. studied strategies employed by professional online dating coaches [42] while Masden and Edwards reveal how "outsourced communities" thrive in external forums sharing tips on how to succeed on these platforms [30].

Ultimately, dating is a category of things, objects, people, and their relations; like all categories, it is historically and politically situated and learned through a community of practice [3]. The studies above show that intimate platforms implicitly and explicitly encourage users to imagine that the traits of individual humans are market commodities traded based on their romantic exchange value [19].

\section{Architects of Intimacy}

There are numerous intimate platforms currently out in the market. Surveying the system design of various intimate platforms, Tong et. al. created a three-part taxonomy of such platforms: (1) see-and-screen, in which the user is able to select their favored profiles from a swath of options, (2) algorithm, in which a user is presented with an algorithmically calculated 'best match', and (3) blended, in which some features from both are employed [38]. While intimate platforms

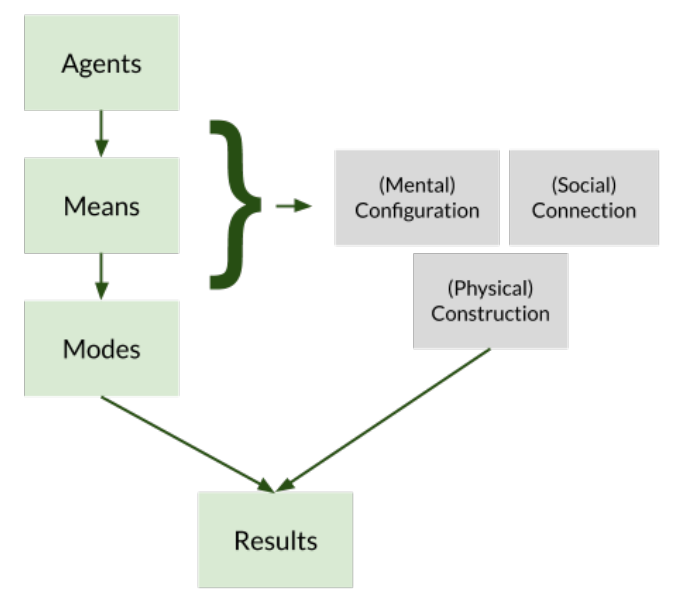

Figure 1. Schematic of the document model, adapted from [22], showing how agents, through specific means and modes, arrive at results in the documentation process.

are being marketed differently, they do share the same market logic and a design philosophy that aims to unburden users by requiring "less time and emotional investment to play" [20].

Previous studies $[5,6,16,33]$, however, have shown that intimate platforms are also designed with bias that "provide easy-to-use features that allow users to act on (discriminatory) preferences" [21]. Tarleton Gillespie asserts that giving users perceived control does not relieve platforms of their responsibilities towards the social interactions they mediate [18]. If designers of intimate platforms are "architects of intimacy," Hutson et. al. call for bias and discrimination to be mitigated through design. Their paper lays out how affordances, seamfulness, and friction can be evaluated and introduced to debias prominent design features of intimate platforms: search, sort, and filter tools; matching by algorithm; and community policies and messaging [21].

While these design changes may help address intimate discrimination, they may also effectively shroud a phenomenon that remains almost purely mercenary. The commercial motivations of intimate platforms and its mechanisms of data capture, aggregation, and resale cannot simply be abolished by design thinking alone. The task at hand then is to make visible these operations by looking at intimate platforms as sociotechnical systems entrenched in market logic.

\section{Documents of Intimacy}

Olsen et. al. propose a novel document model as a potential approach and tool for understanding sociotechnical systems [22]. Drawing from the established field of documentation studies, the model is grounded in the idea that social relations are increasingly mediated and governed by documents [4, 15]. "Document" in this model encompasses objects other than traditional written documents. It refers to any object produced by human agents through particular instruments that allow it to be 
perceived cognitively, socially, and physically. "Documentation" then is the process where an object is made as, made into, and/or considered as a document [4]. The process requires an agent as a producer, a set of tools, a mechanism to utilize such tools, and the resulting document [27]. Documentation unfolds in time, shaped and constrained by any number of factors, some of which are easy to recognize, others of which necessitate a close analysis of the process itself. Through technologies, genres, modes of inscription, and forms of expression, something becomes evident as it comes into presence, or what Ronald Day [10] calls "documentarity," which calls for the examination of both the documentary evidence and documentation process in interrogating such "technologies of judgment."

The value of document theory to sociotechnical systems design as proposed by Olsen et. al. is based on the hypothesis that describing documents, particularly the process of creating them, can lead to better critiques of the system. It calls for "a holistic approach starting with looking at what constitutes the meaningful whole in a document - what goes into it and where the boundaries for the document are" [22]. Document theory is not meant to replace any other approaches or concepts in $\mathrm{HCI}$, rather it serves as a "taxonomy or template in which to place more detailed analysis of the documents residing within and influencing our diverse human cultures" [22]. Its strength lies in its ability to complement and expand user and design thinking. Holistic and specific analyses can be done by looking at systems and their components as processes of documentation and a network of documents.

The model, shown in Figure 1, identifies agents, who through specific means and modes, create a document as a result. Each stage of this creation process is shaped by mental configuration, social connection, and physical construction [22]. Olsen et. al.'s proposed document model of analysis has been applied in analyzing a store-and-forward psychiatry system [31] and in determining means to curtail the counterproductive information security behaviours of federal employees [37]. Similar to these works, our application of document theory in studying intimate platforms will make visible how dating profiles as documents are "created to construct and enforce hierarchies of power, or govern social relations within or between groups or cultures," [22].

Olsen et. al. state that the starting point of any document analysis is to describe the goal of the document and the system that utilizes it [22]. As we have argued through our literature review, the goal of intimate platforms, being entrenched in market logic, is ultimately maximizing profit extraction. Our objective in this study is to make this goal visible through document analysis of the material aspects of dating profiles, to support and critique incremental design changes while also calling for broader alternatives to be imagined.

\section{METHODS}

This study investigated intimate platforms following the theoretical framework proposed by Olsen et. al. [22]. We focused on dating profiles as documents for analysis. Our sample consisted of the ten most popular online dating apps in the United
States as of March 2019, as measured by audience size [7]: Tinder, Plenty of Fish, Bumble, OK Cupid, Match.com, Grindr, Zoosk, MeetMe, Scruff, and OurTime. These applications are targeted to a variety of audiences, including individuals of all sexual orientations (Tinder, Plenty of Fish, OK Cupid, MeetMe, Zoosk), women seeking to minimize unwelcome solicitations (Bumble), men seeking encounters with other men (Grindr, Scruff), and older adults seeking encounters with others over the age of 50 (Our Time). The apps are set up with a variety of interaction styles. A swiping format is most common, where the user is presented with a sequence of other profiles on the platform and makes a binary selection of whether or not they are interested. Variations on this format include different degrees of marketing a curated set of potential matches, different requirements for who may express interest first, different visibility of whether the other party has already expressed interest, and different requirements for matching in order to chat. Some apps such as Grindr have a grid format, where all co-located users are visible in a grid layout and matching is not required to chat.

Despite these variations in the intimate platforms' marketing approaches and interfaces, we wanted to determine the extent to which dating profiles constitute a genre of document. To do this, we studied the process of making a profile for each platform. We documented every field asked in the process of creating a profile, whether such fields were required or not, the available values for populating the field, the means for inputting said values, and the limits for inputting them. Table 1 summarizes applications included in this study.

The first two authors coded the dating profile fields. The first author mapped and worked with all of the authors to categorize types of fields that appeared across the applications. Mapping the fields and types of fields present allowed us to determine the shape of the "casting mold" of dating profiles, or the "template for making documents of that kind" [22]. This includes the "prerequisites... for making such a document and the process of how it should come into existence," [22]. We further employed a document analysis approach following Frohmann's work on seeking analogy, similarity, differences, and resemblances between documents [17]. We complied descriptive statistics to determine the commonality of fields and their attendant features across the platforms we investigated.

We looked at dating profiles as documents and their creation as a process of documentation. Our analysis followed the framework laid out by Olsen et. al. in applying document theory to analyze sociotechnical systems [22]. The document model, shown in Figure 1, illustrates how this theory is divided into seven components that describe the document holistically. The first four - (1) agents, (2) means, (3) modes, and (4) results - form the casting mold for the document. The description and analysis of this casting mold form the scope of this current study. Adopting the model's line of inquiry, we sought to answer the following questions and present our findings accordingly.

1. Agent: Who produces the dating profile?

2. Means: What is used to produce the dating profile? 


\begin{tabular}{lllr}
\hline Application & Version & Developer & Corporate Owner \\
\hline Tinder & v. 10.17 .0 & Tinder Inc. & IAC Match Group, Inc \\
Plenty of Fish & v. 11.10 .1568 & PlentyOfFish & IAC Match Group, Inc \\
Bumble & v. 5.126 .0 & Bumble Holding Limited & Bumble Trading Inc \\
OkCupid & v. 31.3 .0 & OkCupid & IAC Match Group, Inc \\
Match.com & v. 19.09 .01 & Match Group, LLC & IAC Match Group, Inc \\
Grindr & v. 5.14 .0 & Grindr LLC & Kunlun Tech Co Ltd \\
Zoosk & v. 8.17 .8 & Zoosk, Inc & Spark Networks SE \\
MeetMe & v. 14.1 .0 & MeetMe, Inc & The Meet Group, Inc \\
Scruff & v.6.0102 & Perry Street Software, Inc & Perry Street Software, Inc \\
OurTime & v. 2.0 .14 & People Media, Inc & IAC Match Group, Inc \\
\hline
\end{tabular}

Table 1. The top ten dating apps in the US in March 2019, the version used in this study, and the developer and corporate owner of each app.

3. Modes: How is the dating profile produced and reproduced?

4. Result: What is the identifiable product of this documentation process?

Considering the document through the lens of these four components allows the description and analysis not only of the document in question, but also of the processes of documentation and the system as a whole. The last three components of the model - (5) mental configuration, (6) social connection, and (7) physical construction - comprise the "complementary analysis" of the document, enabling further understanding of the document in situ [22]. As they require a different set of methodologies, these components are beyond the scope of this current study, but we intend to pursue them in future work.

\section{FINDINGS}

Following the document model described above, we discuss the agent, means, mode, and result that we found across the ten dating apps we investigated.

\section{The Agents: Who Produces the Dating Profile?}

The collection of agents is the first component of the document model. Driven by particular motivations, agents are the ones who produce the document in question. The nature of the document and the process of documentation are directed by these motivations and by the dynamics between the agents involved [22].

Users of intimate platforms are prompted to "create your own profile," giving a sense of full ownership of the process and of the result of the documentation. Our analysis of the fields populated on dating profiles, who populates them, and how they are populated, tells a different story.

Fields are populated either by the user or populated automatically by the platform. User-generated fields can either be an open field which allows open-text entry or a fixed field which provides limited preset options from which the user is to choose. Certain fields were system-generated with the user having no direct role in inputting information. Figure 2 summarizes the distribution of fields populated by the user and the system, and in the case of the former, specifies the proportion of fields that are open or fixed. Of the 18 common fields that are asked across the ten dating profiles in this study

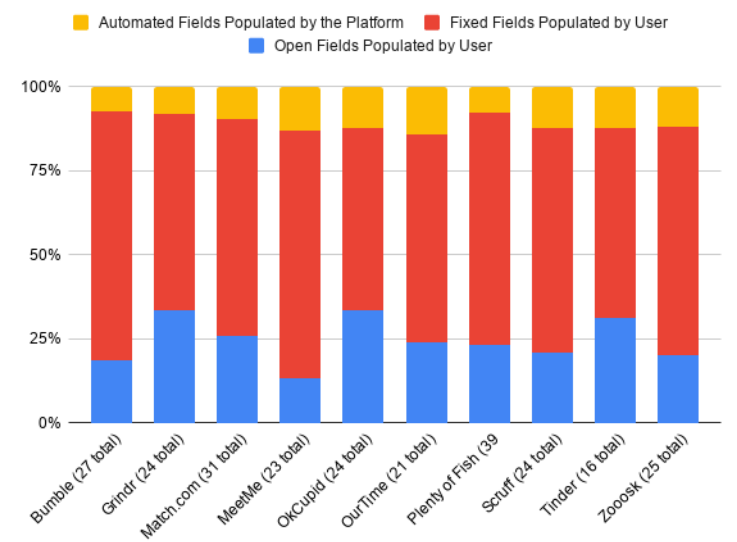

Figure 2. Percentage of Open, Fixed, and Automated Fields Among Intimate Platforms

(see Table 2), the majority of them are fixed fields, which limit the freedom of the user during profile creation.

We can then see that the dating profile is not the sole creation of the user. Rather, our findings show that the dating profile is a negotiated document, created, shaped, and constrained by the system as well. The profile therefore is not just the self-representation of the user; the profile is never a person.

Users are motivated to create profiles for a variety of intimate reasons including finding love, hooking up, and fooling other users. The developer and corporate owner of these intimate platforms participate in the creation of these profiles for different reasons [8, 35, 36, 41]. The intimate motivations of the users are but means to a profitable end for the corporation. In the end, both the user and the intimate platform are responsible for the creation of the object, and consequently both participate willingly or unwillingly in the overall system of profit extraction.

\section{The Means: What is used to produce the dating profile?}

The means refer to the instruments that enable the documentation to happen. The process of creating a document necessitates a system of input as well as output mechanisms and technologies, broadly defined [22]. Analyzing the means of 


\begin{tabular}{|c|c|c|c|c|c|}
\hline Field & Asked & Mandatory & Optional & Not Asked & Open, Fixed, or Automated \\
\hline Distance/Location & $100 \%$ & $100 \%$ & $0 \%$ & $0 \%$ & Automated \\
\hline Age & $100 \%$ & $90 \%$ & $10 \%$ & $0 \%$ & Fixed or Automated \\
\hline Display/User/Profile Name & $100 \%$ & $90 \%$ & $10 \%$ & $0 \%$ & Open \\
\hline Photo & $100 \%$ & $50 \%$ & $50 \%$ & $0 \%$ & Open \\
\hline Birthday & $90 \%$ & $90 \%$ & $0 \%$ & $10 \%$ & Fixed \\
\hline Gender (I am a...) & $90 \%$ & $80 \%$ & $10 \%$ & $10 \%$ & Fixed \\
\hline About Me/Description & $90 \%$ & $20 \%$ & $70 \%$ & $10 \%$ & Open \\
\hline Show me/Interested In/Seeking (...gender) & $80 \%$ & $80 \%$ & $0 \%$ & $20 \%$ & Fixed \\
\hline Last Seen Online/Online Status & $80 \%$ & $80 \%$ & $0 \%$ & $20 \%$ & Automated \\
\hline I'm Looking For/(Reason for app use) & $80 \%$ & $40 \%$ & $40 \%$ & $20 \%$ & Fixed \\
\hline City/Living in... & $80 \%$ & $40 \%$ & $40 \%$ & $20 \%$ & Open or Fixed \\
\hline Height & $80 \%$ & $30 \%$ & $50 \%$ & $20 \%$ & Fixed \\
\hline Ethnicity & $80 \%$ & $30 \%$ & $50 \%$ & $20 \%$ & Fixed \\
\hline Educational Level & $70 \%$ & $20 \%$ & $50 \%$ & $30 \%$ & Fixed \\
\hline Smoking habits & $70 \%$ & $20 \%$ & $50 \%$ & $30 \%$ & Fixed \\
\hline Kids/Children (Do you have/want kids?) & $70 \%$ & $20 \%$ & $50 \%$ & $30 \%$ & Fixed \\
\hline Religion/Religious Beliefs & $70 \%$ & $20 \%$ & $50 \%$ & $30 \%$ & Fixed \\
\hline Job Title/Career/Profession/Occupation & $70 \%$ & $10 \%$ & $60 \%$ & $30 \%$ & Open or Fixed \\
\hline
\end{tabular}

Table 2. The most commonly-asked fields in the intimate platforms surveyed.

documentation is not only a window to a technical process, it can also make visible embedded politics of valuation.

In the case of intimate platforms, these embedded politics can be seen in the technical requirements to run an intimate platform, conditions for entry, and legal restrictions for use. The ten platforms studied all share these means as instruments that enable documentation to happen.

Before a user can begin to make a profile, and therefore before a user can interact on the intimate platform, a variety of infrastructural prerequisites must be met. The primary prerequisites are ownership of a smartphone and continued access to the internet. To be able to open an account and make a profile on these intimate platforms, at least one of the following conditions for entry are required: an active mobile number, an email address, and/or a social media account. Finally, users must agree to legal restrictions in the form of an end user license agreement (EULA) and a legal age restriction checked by self-reporting one's date of birth. In addition to these, once on the platform, users are asked and at times required to grant the platform access to the phone's location-based services and camera to experience the full functionality of the app.

Looking at these means to produce a dating profile, we can see how intimate platforms already discriminate at the point of entry. Access to these means requires and implies a certain amount of material capital. The infrastructure and resources needed to continuously partake in the system already sifts through the population. Not everyone has access to mobile phones or seamless data connection. Design changes to the platform [21] are unable to mitigate this economic bias.

The Modes: How is the dating profile produced and reproduced?

The mode, in the context of creating a document, refers to both the ways the agents communicate with each other and the ways the means are used. In particular, it is the "degrees of freedom" (Bolter and Bolter, 2001) that agents have in terms of authoring (creating) and reproducing (making visible) the document [22].

Our findings and earlier analysis of agents show how users of intimate platforms have limited mode (i.e. limited ability to use the means) in terms of freely authoring their profiles. The set fields and fixed values that are available to populate those fields, together with the ones generated by the system, constrain the user as an author. While it can be argued that these constraints actually provide users a convenience to efficiently create profiles, studies have shown that these constraints fail to be inclusive and are discriminatory [21]. The constraints do make things efficient, not for the user, but rather for the system, towards its goal of object classification for profit extraction.

When it comes to the mode of reproducing the profile, in terms of its presentation and visibility on the platform, users generally have more fields under their control, as seen in Figure 3. Users can make these fields visible or not to other users by choosing to hide them or by opting not to answer them at all. Platforms also actively limit the user's ability to control the visibility of some fields, particularly the systemgenerated ones (age, online status, and location). The only way to lift these constraints, if there is a way, is to pay for a premium subscription.

With regards to the visibility of the document/profile as a whole on the platform, users generally do not have control when it comes to how their profile shows up and who their profile is shown to. Control may be granted to users through subscription fees which allow them to stand out in searches (POF), boost the likelihood their profiles will be shown to others (Tinder, POF, Match), or hide their profile all together (Grindr and Scruff). 


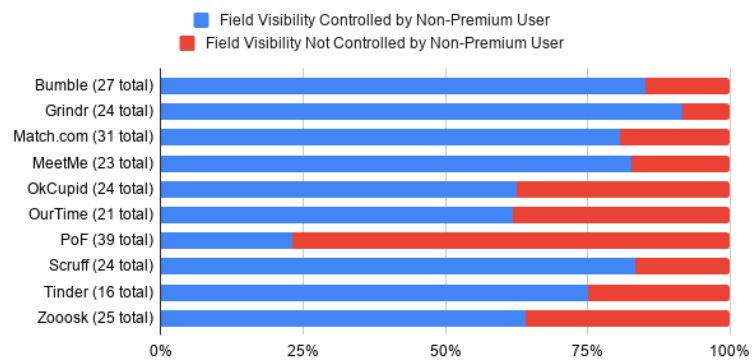

Figure 3. Percentage of Fields Where Non-Premium Users can Control Visibility of the Field on the User's Profile

The general mode (i.e. ability to use the means) of the user to author and reproduce their profiles is artificially and intentionally limited by the corporations controlling the platforms. Users can be freed of some of these constraints and gain a little more control only after paying for premium subscriptions. The profit motivations of the developer are clearly seen as they shape the modes of documentation.

\section{The Result}

The result is the product of documentation and constitutes the end of the process. It is shaped by the agents, means, and modes together with the abstractions of configuration, connection, and construction [22].

In looking at dating profiles as the resulting product of documentation, together with the process itself and its components, the casting mold of intimate platforms is given shape. Specifically, we accomplish this by identifying and analyzing the 65 unique fields across the ten intimate platforms we studied. While dating platforms consist of variable fields (Figure 4), 18 fields are commonly asked (by seven or more out of the ten apps, see Table 2), forming the casting mold. The rest of the fields that vary from platform to platform are variable attributes that are aimed at and utilized for specific target markets and functions.

These intimate platforms, given this casting mold, are homogeneous in the sense of forming a coherent document type. While users can sometimes opt out from filling in certain fields or even subvert how the fields are expected to be populated, users are unable to create new fields or change this casting mold. This is because, as we have seen in our analysis of the agent, means, and modes, the casting mold is not primarily for self-representation but rather for object creation. The control of the documentation process principally lies with the system, which aims to extract profit via invisibilization of labor in digital networks, leading to the emergence of a constrained rational market actor.

\section{DISCUSSION}

\section{Intimate Platforms as Heteromated Systems}

Our analysis illustrated the ways in which dating profiles, crafted through a casting mold, are homogeneous objects in service of profit extraction. Dating profiles, created through the tensions between users and developers, are not people, nor

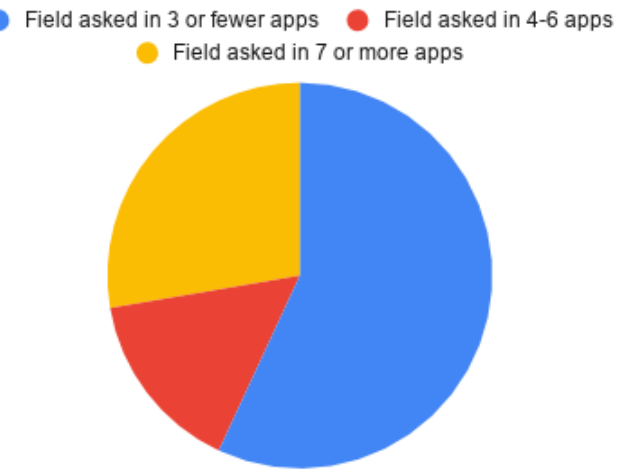

Figure 4. Distribution of How Often Each Field was Asked in the 10 Apps Surveyed

are they self-representations of individuals. Rather, the user and the developer, in co-creating the dating profile, are both contributing labor from which the corporations that own intimate platforms extract value. These findings show how the process of creating dating profiles is a form of heteromated labor. Heteromation refers to "the extraction of economic value from low-cost or free labor in computer-mediated networks," [13]. Users are not paid to participate in the networked arrangement of an intimate platform, and in many cases users directly pay for certain forms of participation. However, their labor in creating profiles (and in interacting on the platform, which is beyond the scope of this paper to empirically investigate) generates value to corporations, a value that is invisiblized in most studies of intimate platforms.

Ekbia and Nardi write, "Despite our best intentions as designers, technologists, and users, the conditions produced by the dominant political economy cannot be wished away," [11]. Applying document theory to dating profiles allows us to level different critiques at intimate platforms than allowed by a focus on design features and their impact on user experience. With the dating profile as a unit of analysis, and a critical view of how the goal of the document is achieved through the documentation process, we are able to reveal the fundamentally extractive nature of intimate platforms. Failure to engage with the political and make explicit the extractive, non-neutral nature of technical infrastructures, including intimate platforms, will continue to entrench systematic inequalities promoted by the system and continue to invisiblize the labor and extractions of privately-owned networked systems that uptake masses of users.

\section{The Emergence of the Romantic Liberal}

Intimate platforms, based as they are on market logic, pose a number of provocative questions about the range of possible expressions permissible through the use of the technology. The operation of intimate platforms, seen in this study as a process of documentation, is a point of entry to revealing the dating profile as a document at the center of intimate platforms. The dating profile then is the result of documentation that categorizes the self as a means of both identity formation and capital object creation. 
This process unfolds in several steps. First, the user agrees to document him/herself into an object of potential. As Elison et. al. note, authors/readers of dating profiles interpret dating profiles as potential selves, idealized versions of a self that they can eventually deliver [14]. Second, rules must be established for how this object of potential is to be accomplished through documentation. Intimate platforms, as we have shown in our findings, function on a number of highly specific rules that form its casting mold: (1) there are requirements and barriers to entry that limit participants to those who are deemed valuable; (2) the process of profile creation is negotiated, shaped, and constrained by the platform; and (3) the platform is designed with intentional limits that can only be lifted through paid premium subscriptions. Third, the documentation places the user in a confined information space that is imagined to be a romantic marketplace.

Thus the subject of online dating emerges as a kind of romantic liberal, a rational market agent who can express different kinds of moods and affects to other users through the means and modes of the intimate platform, but whose market autonomy with regard to the extractive regime of participation in which he or she operates is incredibly limited. The agent surrenders to the logic of the market as it follows and trusts the documentation process of the platform until the gains outweigh the costs. Valuation happens in use, in how an intimate platform user, created into a document, operates in an environment ordered by a technology that presupposes and shapes behavior but pretends subservience to the market agency of the user. Ultimately, intimate platforms function amid an ideological and political environment that reduces all of society's interactions and institutions to market logic, with its presumption of rationality, autonomy, and choice. The romantic liberal is then indicative of the emerging subject of the contemporary consumer who is a producer of data, an object of individual, corporate, and state surveillance, and a voracious consumer of all kinds of informatized and mediatized communications.

\section{Making the "Program of Action" Visible Through Docu- ment Theory}

As Ekbia noted in a provocative work on a philosophical paradox at the heart of artificial intelligence research, depictions of technology tend to erase "the complex surrounding support structure provided by human beings, devices, and infrastructures, in the same fashion that media portrayals of chess contests between human and machine take out of the picture the critical role of humans as surrogate players, spectators, analysts, and so forth" [12]. This erasure amounts to more than a question of accuracy of representation; it indicates a deep philosophical contradiction held by experts and the general public alike concerning agency, autonomy, and technical systems. As van Dijck argued, the functioning of user-generated content proves methodologically complex [39]. User agency is conceptualized here as a multifarious phenomenon, that includes a user's "cultural role, as facilitator of civic engagement and participation, but also his[sic] economic meaning as a producer consumer, and data provider, as well as the user's volatile position in the labor market" [39]. In both works, the authors attempt to force the necessary labor of humans in all its varieties back into the understanding of the political economy of contemporary technology. Who is the user whose needs are anticipated by (and whose behavior is simultaneously controlled by) the elaborate, sprawling technological systems that infiltrate, order, and constrain daily life?

In this study, we showed how the concept of a document and documentation along with a document model can be employed to (re)introduce the user as an agent who engages with the intimate platform through specific means and modes into a critical understanding of that particular sociotechnical system. Our study illustrates how document theory makes visible the ways in which these various components of computation, as a process of documentation, govern our everyday life.

As Olsen et. al. note, "Document analysis is both a novel concept and a very old one," [22] that responds to Davis' call for a hybridized theory of system design redefined within humanistic inquiry [9]. It allows us to investigate the unfolding of the social via the artefactual document, the "program of action" inscribed in technology as a means of radical critique [25]. Describing and making explicit the assumptions of technological systems used in everyday life calls on us to imagine alternatives beyond incremental design changes and consider broader structural realities.

\section{CONCLUSION}

In response to Hutson et. al.'s call to work towards "unsettling entrenched preferences" around intimate platforms, we present document theory as a mechanism to more broadly analyze intimate platforms as sociotechnical systems [21]. Through our analysis, we argue that dating profiles are not people but rather documents with a "casting mold" designed for profit extraction, perpetuating structural inequalities beyond intimate discrimination which incremental design changes inadequately addresses.

Is it possible then to design a non-extractive casting mold for intimate platforms? Following our arguments and given the nature of intimate platforms we have studied, it is unlikely. By being suspicious of and reckoning with imbalanced distributions of power [23] in processes of documentation, we want to point out the inequalities embedded in and perpetuated by intimate platforms. Further issues relating to system control, regulation, and visibility as tied to cognitive labor and enduser behavior are all integral in exploring this. Future work will focus on complementary analysis included in Olsen et. al.'s approach, which calls for employing a variety of established approaches in HCI to study the user and their context. Our study focused on four parts of the intimate platform as a document - its agents, means, modes, and results. The findings, analysis, and discussions we present here can be further explored by subsequent studies utilizing the remaining three parts of the model (configuration, connection, and construction) which necessitate methodologies beyond what we employed. This includes, for example, analyzing intimate platforms' (1) mental configuration through cognitive task analysis, (2) social connection using ethnomethodology, and (3) physical construction via material assessments. 
Through our analysis of intimate platforms, we have shown that document theory can be used in HCI. By looking at sociotechnical systems as networks of documents and series of documentation processes, assumptions are methodologically and empirically laid bare. This allows a fundamental political economic critique for us "to challenge structures of oppression and support human dignity" [23] leading us to imagine alternative systems entirely. Our future work will continue to utilize document theory in pursuing social justice in HCI research.

\section{ACKNOWLEDGMENTS}

We thank our undergraduate research assistant, Alice Lee, and our colleagues in the Evoke Lab and Studio. We appreciate Professor Christopher Kelty's support on an earlier version of this project. Finally, the authors also wish to thank Os Keyes, Josephine Hoy, and Margaret Drouhard for helping us to understand the field of HCI and inviting us to contribute and engage.

\section{REFERENCES}

[1] Aaron C. Ahuvia and Mara B. Adelman. 1992. Formal Intermediaries in the Marriage Market: A Typology and Review. Journal of Marriage and the Family 54, 2 (May 1992), 452. DOI : http://dx.doi .org/10.2307/353076

[2] Jeremy Birnholtz, Colin Fitzpatrick, Mark Handel, and Jed R. Brubaker. 2014. Identity, identification and identifiability: the language of self-presentation on a location-based mobile dating app. In Proceedings of the 16th international conference on Human-computer interaction with mobile devices \& services - MobileHCI '14. ACM Press, Toronto, ON, Canada, 3-12. DOI : http://dx.doi.org/10.1145/2628363.2628406

[3] Geoffrey C. Bowker and Susan Leigh Star. 2000. Sorting things out: classification and its consequences (first paperback edition ed.). The MIT Press, Cambridge, Massachusetts London, England. OCLC: 247920023.

[4] Michael Buckland. 2014. Documentality Beyond Documents. The Monist 97, 2 (2014), 179-186. https://www. jstor.org/stable/44012677

[5] Denton Callander, Martin Holt, and Christy E. Newman. 2012. Just a preference: racialised language in the sex-seeking profiles of gay and bisexual men. Culture, Health \& Sexuality 14, 9 (Oct. 2012), 1049-1063. D0I : http://dx.doi.org/10.1080/13691058.2012.714799

[6] Denton Callander, Martin Holt, and Christy E. Newman. 2016. 'Not everyone's gonna like me': Accounting for race and racism in sex and dating web services for gay and bisexual men. Ethnicities 16, 1 (Feb. 2016), 3-21. DOI : http://dx.doi.org/10.1177/1468796815581428

[7] J. Clement. 2019. Most popular online dating apps in the United States as of March 2019, by audience size (in millions). (2019).

https://web.archive.org/web/20190819193550/https: //www.statista.com/statistics/826778/ most-popular-dating-apps-by-audience-size-usa/

[8] Roderic N. Crooks. 2013. The Rainbow Flag and the Green Carnation: Grindr in The Gay Village. First
Monday 18, 11 (Nov. 2013). DOI :

http://dx.doi.org/10.5210/fm.v18i11.4958

[9] Marc Davis. 2003. Theoretical foundations for experiential systems design. In Proceedings of the 2003 ACM SIGMM workshop on Experiential telepresence ETP '03. ACM Press, Berkeley, California, 45. DOI : http://dx.doi.org/10.1145/982484.982491

[10] Ronald E Day. 2019. Documentarity: Evidence, Ontology, and Inscription. MIT Press.

[11] Hamid Ekbia and Bonnie Nardi. 2016. Social Inequality and HCI: The View from Political Economy. In Proceedings of the 2016 CHI Conference on Human Factors in Computing Systems - CHI'16. ACM Press, Santa Clara, California, USA, 4997-5002. DOI : http://dx.doi.org/10.1145/2858036.2858343

[12] Hamid R. Ekbia. 2015. Heteronomous Humans and Autonomous Agents: Toward Artificial Relational Intelligence. In Beyond Artificial Intelligence: The Disappearing Human-Machine Divide, Jan Romportl, Eva Zackova, and Jozef Kelemen (Eds.). Springer International Publishing, Cham, 63-77. DOI : http://dx.doi .org/10.1007/978-3-319-09668-1_5

[13] Hamid R. Ekbia and Bonnie A. Nardi. 2017. Heteromation, and other stories of computing and capitalism. MIT Press. 2018-09-17.

[14] Nicole B. Ellison, Jeffrey T. Hancock, and Catalina L. Toma. 2012. Profile as promise: A framework for conceptualizing veracity in online dating self-presentations. New Media \& Society 14, 1 (Feb. 2012), 45-62. DOI :

http://dx.doi.org/10.1177/1461444811410395

[15] Maurizio Ferraris. 2013. Documentality - Or why nothing social exists beyond the text. From ontos verlag: Publications of the Austrian Ludwig Wittgenstein Society - New Series (Volumes 1-18) 3, 0 (Oct. 2013). http://wittgensteinrepository.org/agora-ontos/ article/view/2015

[16] Eli J. Finkel, Paul W. Eastwick, Benjamin R. Karney, Harry T. Reis, and Susan Sprecher. 2012. Online Dating: A Critical Analysis From the Perspective of Psychological Science. Psychological Science in the Public Interest 13, 1 (Jan. 2012), 3-66. DOI : http://dx.doi.org/10.1177/1529100612436522

[17] Bernd Frohmann. 2009. Revisiting "what is a document?". Journal of Documentation 65, 2 (March 2009), 291-303. DOI : http://dx . doi .org/10.1108/00220410910937624

[18] Tarleton Gillespie. 2010. The politics of 'platforms'. New Media \& Society 12, 3 (May 2010), 347-364. DOI : http://dx.doi.org/10.1177/1461444809342738

[19] Rebecca D. Heino, Nicole B. Ellison, and Jennifer L. Gibbs. 2010. Relationshopping: Investigating the market metaphor in online dating. Journal of Social and Personal Relationships 27, 4 (June 2010), 427-447. DOI : http://dx.doi .org/10.1177/0265407510361614 
[20] Mitchell Hobbs, Stephen Owen, and Livia Gerber. 2017. Liquid love? Dating apps, sex, relationships and the digital transformation of intimacy. Journal of Sociology 53, 2 (June 2017), 271-284. DOI : http://dx.doi.org/10.1177/1440783316662718

[21] Jevan A. Hutson, Jessie G. Taft, Solon Barocas, and Karen Levy. 2018. Debiasing Desire: Addressing Bias \& Discrimination on Intimate Platforms. Proceedings of the ACM on Human-Computer Interaction 2, CSCW (Nov. 2018), 1-18. DOI : http://dx.doi.org/10.1145/3274342

[22] Bernt Ivar Olsen, Niels Windfeld Lund, Gunnar Ellingsen, and Gunnar Hartvigsen. 2012. Document theory for the design of socio-technical systems: A document model as ontology of human expression. Journal of Documentation 68, 1 (Jan. 2012), 100-126. DOI: http://dx.doi.org/10.1108/00220411211200347

[23] Os Keyes, Josephine Hoy, and Margaret Drouhard. 2019. Human-Computer Insurrection: Notes on an Anarchist HCI. In Proceedings of the 2019 CHI Conference on Human Factors in Computing Systems. ACM, 339.

[24] John LaRosa. American Singles Fuel the \$2.5 Billion Dating Market. Technical Report. https://blog . marketresearch. com/ american-singles-fuel-the-2.5-billion-dating-market

[25] Bruno Latour. 1992. Where are the Missing Masses? The Sociology of a Few Mundane Artifacts. Shaping technology/building society: studies in sociotechnical change. WE Bijker and J. Law. WE Bijker, J. Law, \& American Council of Learned Societies (Eds.), Shaping technology/building society: studies in sociotechnical change (1992), 225-258.

[26] Steven Levitt. 2013. The 2013 TIME 100: Sam Yagan, Matchmaker. Time (2013). http://time100. time.com/ 2013/04/18/time-100/slide/sam-yagan/

[27] Niels Windfeld Lund. 2004. Documentation in a complementary perspective. (2004).

[28] Xiao Ma. 2017. What Happens in Happn: The Warranting Powers of Location History in Online Dating. In Proceedings of the 2017 ACM Conference on Computer Supported Cooperative Work and Social Computing - CSCW' 17. ACM Press, Portland, Oregon, USA, 41-50. DOI :

http://dx .doi .org/10.1145/2998181.2998241

[29] John Madigan. 2019. Dating Services in the US. IBISWorld Industry Report 81299a. IBISWorld Services, Melbourne, Australia. http://clients1.ibisworld.com/ reports/us/industry/default . aspx?entid=1723

[30] Christina Masden and W. Keith Edwards. 2015. Understanding the Role of Community in Online Dating. In Proceedings of the 33rd Annual ACM Conference on Human Factors in Computing Systems - CHI '15. ACM Press, Seoul, Republic of Korea, 535-544. DOI: http://dx.doi.org/10.1145/2702123.2702417
[31] Bernt Ivar Olsen, Peter M. Yellowlees, Alberto Odor, Niels Windfeld Lund, and Gunnar Hartvigsen. 2013. Document Analysis (DA) as a Sociotechnical Design Framework for HCI: A Novel Tele-psychiatric Service as a Case Study. In HCI International 2013 - Posters' Extended Abstracts, Constantine Stephanidis (Ed.). Vol. 373. Springer Berlin Heidelberg, Berlin, Heidelberg, 65-68. DOI :

http://dx.doi .org/10.1007/978-3-642-39473-7_14

[32] Jennifer Phegley. 2012. Courtship and marriage in Victorian England. Praeger, Santa Barbara, Calif. OCLC: ocn712115037.

[33] Russell K. Robinson. 2008. Structural Dimensions of Romantic Preferences. Fordham Law Review 76 (May 2008), 2787-2819.

https: //papers. ssrn. com/abstract $=1130968$

[34] Philip Roscoe and Shiona Chillas. 2014. The state of affairs: critical performativity and the online dating industry. Organization 21, 6 (Nov. 2014), 797-820. DOI : http://dx.doi .org/10.1177/1350508413485497

[35] Michael J. Rosenfeld and Reuben J. Thomas. 2012. Searching for a Mate: The Rise of the Internet as a Social Intermediary. American Sociological Review 77, 4 (Aug. 2012), 523-547. DOI : http://dx.doi.org/10.1177/0003122412448050

[36] Aaron Smith. 2016. 15\% of American adults use online dating sites or mobile apps. (Feb. 2016).

[37] Richard Allan Tanoh. 2017. Diminishing Federal Employees' Counterproductive Information Security Behaviors: A Multiple Case Study. Ph.D. Northcentral University, United States - California.

https://search.proquest. com/docview/1968655519/ abstract/579B96BDE6424908PQ/1

[38] Stephanie T. Tong, Jeffrey T. Hancock, and Richard B. Slatcher. 2016. Online dating system design and relational decision making: Choice, algorithms, and control: System design in online dating. Personal Relationships 23, 4 (Dec. 2016), 645-662. DOI: http://dx.doi.org/10.1111/pere. 12158

[39] José van Dijck. 2009. Users like you? Theorizing agency in user-generated content. Media, Culture \& Society 31, 1 (Jan. 2009), 41-58. DOI : http://dx.doi.org/10.1177/0163443708098245

[40] Mark Warner, Juan F. Maestre, Jo Gibbs, Chia-Fang Chung, and Ann Blandford. 2019. Signal Appropriation of Explicit HIV Status Disclosure Fields in Sex-Social Apps used by Gay and Bisexual Men. In Proceedings of the 2019 CHI Conference on Human Factors in Computing Systems - CHI '19. ACM Press, Glasgow, Scotland Uk, 1-15. DOI :

http://dx.doi.org/10.1145/3290605.3300922 
[41] Douglas Zytko, Sukeshini A. Grandhi, and Quentin Jones. 2015. Frustrations with Pursuing Casual Encounters through Online Dating. In Proceedings of the 33rd Annual ACM Conference Extended Abstracts on Human Factors in Computing Systems - CHI EA '15. ACM Press, Seoul, Republic of Korea, 1935-1940. DOI : http://dx.doi.org/10.1145/2702613.2732905
[42] Douglas Zytko, Sukeshini A. Grandhi, and Quentin Jones. 2016. Online Dating Coaches' User Evaluation Strategies. In Proceedings of the 2016 CHI Conference Extended Abstracts on Human Factors in Computing Systems - CHI EA '16. ACM Press, Santa Clara, California, USA, 1337-1343. DOI :

http://dx.doi.org/10.1145/2851581.2892482 